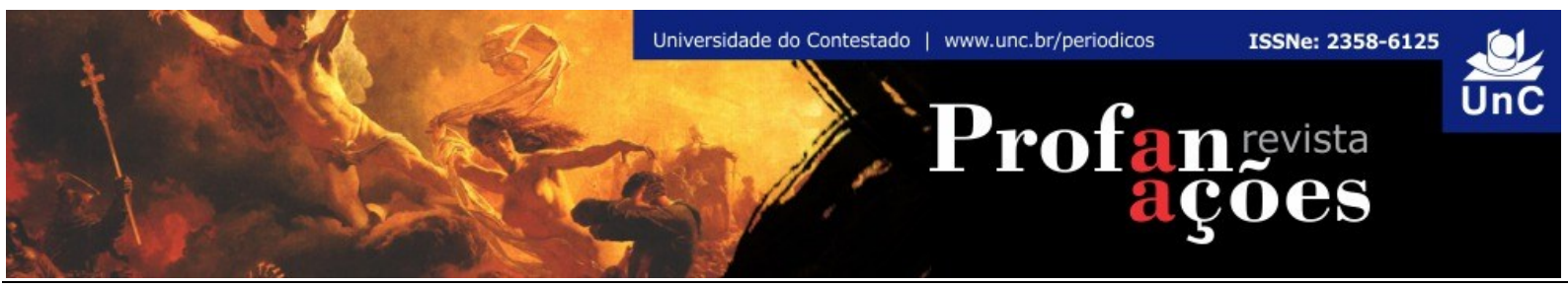

\title{
OPUS DEI - PARA COMPREENDER AS ASSINATURAS TEOLÓGICAS DA ÉTICA NO OCIDENTE
}

Giovanni Felipe Catenaci ${ }^{1}$

RESUMO: Este artigo tem por finalidade introduzir os(as) leitor(as) no universo de Opus Dei: arqueologia do ofício (2015), quando Giorgio Agamben vai em busca de analisar e compreender as razões pelas quais no Ocidente tanto o ser como o agir, são indissociáveis da noção de efetuabilidade. Para tanto, iremos seguir passo a passo a escrita do autor no presente livro, dedicando melhor atenção aos seus conceitos principais, de modo a apresentar as linhas mestras que compõem suas reflexões. Ao final, como sugere o título deste artigo, temos por objetivo ter desvendado as assinaturas teológicas da ética no Ocidente.

Palavras-Chave: Opus Dei. Teologia. Ontologia. Ética.

\section{OPUS DEI - TO UNDERSTAND THE THEOLOGICAL SIGNATURES OF ETHICS IN THE WEST}

ABSTRACT: This Article has the purpose to introduce the readers into the universe of Opus Dei: An Archaeology of Duty; when Giorgio Agamben is searching for analyze and comprehend the reasons why the ocident as in the Being as well in the acting, are inseperable from the notion of effective. Therefore, we will follow step by step of the author's writing in the present book, devoting a better attention to the main concepts, In a way of presenting the master lines composing his reflections. At the end, as sugested by the title of this article, we aim to have unraveled the theological signatures from ocidents ethics.

Key-words: Opus Dei. Theology. Ontology. Ethic.

\footnotetext{
${ }^{1}$ Formado em Teologia pela Universidade Metodista de São Paulo. Pós-graduado em Filosofia Contemporânea e História. Atualmente é doutorando no Programa de Pós Graduação em Ciências da Religião da UMESP, com pesquisa financiada pela CAPES. Brasil. E-mail: giovannicatenaci@hotmail.com. Link para o lattes: http://lattes.cnpq.br/6580978431335745
} 


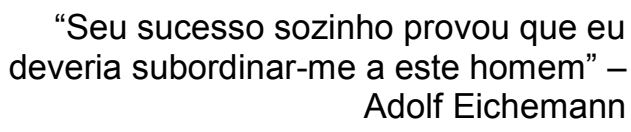

\section{INTRODUÇÃO}

Diferente de Reino e a Glória $^{2}$ quando Agamben se pôs a refletir sobre a liturgia em sua dimensão gloriosa, em Opus Dei: arqueologia do ofício ${ }^{3}$, o filósofo de Roma volta-se para o chão das coisas mesmas. Distanciando-se daquela função que fundamentalmente desempenhavam os anjos, Agamben a fim de compreender a liturgia desde seu aspecto prático-operacional, atém-se às estruturas do ministério sacerdotal e cultico da Igreja. De acordo com as palavras do próprio autor, tratar-seia neste sentido de uma análise do ministério do mistério. Desse modo, em relação ao empreendimento realizado anteriormente no texto de Reino e a Glória, diríamos que aqui Agamben opera um deslocamento-aprofundamento no ângulo de suas análises. Na série que abrange o projeto Homo Sacer, Opus Dei compõe o volume II, 5 .

Não obstante ao rastreamento das assinaturas teológicas da política e da governamentabilidade modernas, evidenciadas naquela já referida genealogia da economia e do governo, o autor italiano vem neste momento trazer à luz o núcleo da máquina ética ocidental. Pretende desvendar seu arcano imperii, por assim dizer. E o que constata é justamente uma outra assinatura teológica. A saber, a noção de "ofício", que segundo Agamben exerceu um influxo profundo na cultura-filosofia ocidental, vindo a balizar o pensamento de figuras importantes, tais como Kant, e as teorias do direito de Kelsen, para citarmos somente dois exemplos. A título de introdução, diríamos em relação à noção de ofício, conforme afirma Agamben, que nele

ser e praxe, aquilo que o homem faz e aquilo que o homem é, entram em uma zona de indistinção, na qual o ser se resolve em seus efeitos práticos e, com uma perfeita circularidade, é aquilo que deve (ser) e deve (ser) aquilo que é. Operatividade e efetualidade definem, nesse sentido, o paradigma ontológico que, no curso de um processo secular, substitui aquele da filosofia clássica: em última análise - esta é a tese que a

\footnotetext{
${ }^{2}$ AGAMBEN, Giorgio. O Reino e a Glória: uma genealogia teológica da economia e do governo. Boitempo: São Paulo. 2011, 236p.

${ }^{3}$ AGAMBEN, Giorgio. Opus Dei: arqueologia do ofício. Boitempo: São Paulo, 2013, 141p.
} 
pesquisa gostaria de propor à reflexão - tanto do ser quanto do agir nós não temos hoje outra representação se não a efetualidade. Real é só o que é efetivo e, como tal, governável e eficaz: a tal ponto o ofício, sob as vestes do simples funcionário ou gloriosas do sacerdote, mudou de alto a baixo tanto as regras da filosofia primeira como as da ética (AGAMBEN, 2013, p. 9).

À vista disso o que está em jogo aqui não é tanto uma história da liturgia cristã, senão, conforme afirma Edgardo Castro, um esforço em prol "de trazer à luz as raízes de uma ontologia dessa efetuabilidade, que domina a política e a ética ocidentais" (CASTRO, 2012, p. 205). A seguir, sondando os caminhos percorridos em Opus Dei, iremos à busca de compreender o inquietante enigma agambeniano acerca do ser e do agir dos quais hoje, nós não temos nenhuma outra representação senão a efetualidade. Efetualidade esta, que de acordo com Agamben, segue desde os mais tempos remotos, subordinando o real àquilo que é efetivo, governável e eficaz.

\section{INVESTIGANDO OPUS DEI: ARQUEOLOGIA DO OFÍCIO}

Bem ao seu estilo, Agamben escolhe como ponto de partida de suas reflexões, a análise etimológica do termo liturgia. Nas palavras do filósofo "Leitourgia (de laos, povo e ergon, obra) significa 'obra pública' e designa, na Grécia Clássica, a obrigação que a cidade impõe aos cidadãos possuidores de certa renda de prover a

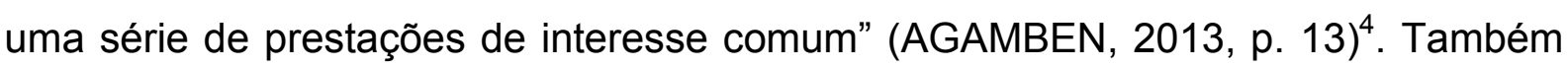
na septuaginta e nas epístolas paulinas o termo liturgia designa o serviço prestado comunitariamente pelo povo. Respectivamente, os rabinos alexandrinos utilizaram leitourgia para traduzirem seret, que quer dizer "servir". De maneira semelhante em Paulo, o termo frequentemente é empregado para referir-se a "prestação de serviços pela comunidade"

\footnotetext{
${ }^{4}$ De acordo com Agamben, tais obras vão desde a "organização dos ginásios e dos jogos gímnicos (gymnasiarchia) à preparação de um coro para as festas da cidade (choregia, a exemplo dos coros trágicos para as Dionisíacas), da aquisição de cereais e óleos (sitegia) a armar e comandar uma trirreme (architheoria) ao adiantamento que os quinze cidadãos mais ricos deviam pagar à cidade sobre as taxas de todo os cidadãos tributáveis (proeisfora)" (AGAMBEN, 2013, p. 14).

${ }^{5}$ É importante dizermos que apesar das variações no emprego do termo na teologia paulina, conforme destaca Agamben, jamais devemos atribuir a pregação de Paulo uma áurea sacrificial. Isso pois, como dissemos, em Paulo, leitourgia diz respeito as várias funções desempenhadas na comunidade.
} 
É somente na Epístola aos Hebreus, quando da elaboração de uma teologia do sacerdócio de Cristo, que o termo liturgia adquire feição estritamente sacerdotal. Lá, afirma Agamben

\begin{abstract}
Não somente sua ação salvífica é apresentada como uma "liturgia", mas, como grande sacerdote de um sacrifício em que o sacrificante sacrifica a si mesmo [...], Cristo realiza uma ação litúrgica, por assim dizer, absoluta e perfeita, que, por isso, pode ser cumprida uma só vez [...]. Nesse sentido, Cristo coincide sem resíduos com sua liturgia - é essencialmente liturgia - e justamente essa coincidência confere a ele sua incomparável eficácia (AGAMBEN, 2013, p.19).
\end{abstract}

Portanto, em polêmica às prescrições sacerdotais do Levítico, cujos sacrifícios deveriam ser continuamente repetidos e renovados de tempos em tempos, no livro de Hebreus, há o anúncio de uma nova aliança que supostamente nulificaria as práticas sacerdotais de oblação. Haja vista que diante da qualidade do sacrifício de Cristo enquanto o grande sacerdote, que é simultaneamente sacrificante e sacrificado como vimos, sua liturgia por ser perfeita é um ato irrepetível. Desse modo, tal qual descrita em Hebreus a ação litúrgica realizada por Jesus não é passível de ser (re)atualizada, afinal Cristo seria o último e mais perfeito dos sacrifícios.

Entrementes, não sem contradições com a teologia do livro de Hebreus, em vista de um conflito que atingiu a comunidade presente em Corinto, "A Epistola de Clemente aos coríntios é o primeiro texto em que uma preocupação pastoral assume a forma de uma teorização da hierarquia eclesiástica compreendida como 'liturgias"' (AGAMBEN, 2013, p.21). Nela, a fim de administrar a situação que se abatia e dividia os fiéis dos chefes da comunidade, Clemente a revelia da cristologia sacerdotal de Hebreus, reivindica o modelo de sacerdócio levítico para fundamentar a sua ideia de sucessão apostólica. Conforme nos diz Agamben

\footnotetext{
Decisivo em sua estratégia, não é tanto o recurso à metáfora militar, que ademais terá na história da igreja uma longa fortuna [...], quanto a ideia de fundar a função dos presbíteros e dos bispos como uma "liturgia" permanente que tem seu modelo no sacerdócio levítico (AGAMBEN, 2013, p. 21).
}

Deste modo, aos poucos a liturgia deixa de ser um serviço comum a todos, vindo a se transformar em uma atividade especial, um ofício vitalício por assim dizer, 
objeto de um cânone específico, em outras palavras: um ministério. Mais tarde, já no Concílio de Trento, formaliza-se institucionalmente a ideia de que é através da eucaristia, isto é, na liturgia da missa, que Cristo enquanto sumo sacerdote da ordem de Melquisedeque transmitiria à hierarquia da igreja, o ministério sacerdotal.

De qualquer forma, como não podemos deixar de notar, em tensão na liturgia cristã, está o esforço por conciliar duas polaridades em tensão: por um lado, conforme a Epístola aos Hebreus, encontramos o mistério do sacrifício irrepetível de Cristo, por outro com a Epístola de Clemente aos coríntios, temos o ministério litúrgico dos bispos e presbíteros, cuja manutenção reside no dever de recordar e renovar àquele sacramento irrepetível. Neste sentido, como afirma Agamben

\begin{abstract}
Aquilo que define a liturgia cristã é, portanto a tentativa aporética, mas sempre reiterada, de identificar coligadamente no ato litúrgico compreendido como opus Dei - mistério e ministério, de fazer coincidir, assim, a liturgia como ato soteriológico eficaz, e a liturgia como serviço comunitário dos clérigos, o opus operatum e o opus operantis Ecclesiae (AGAMBEN, 2013, p.30).
\end{abstract}

E é justamente na distinção entre opus operatum e opus operantis presentes em tensão na liturgia cristã, que a Igreja irá inventar "o paradigma de uma atividade humana cuja eficácia não depende do sujeito que a põe em obra e que necessita dele, contudo, como de um 'instrumento animado' para realizar-se e tornar-se efetiva" (AGAMBEN, 2013, p. 37). Parafraseando Inocêncio III - a contrapelo dos valdenses que questionavam a validade dos sacramentos celebrados pelos sacerdotes indignos -, diríamos que, assim como a enfermidade do médico não compromete o efeito da medicina, de igual modo os pecados dos clérigos não influenciam a obra que realizam. Isso significa dizer que uma vez que a eficácia do sacramento deriva da própria economia mistérica da Trindade, e não se subordina à reta intenção ou pureza do agente que Ihe executa, na liturgia cristã, o liame ético entre sujeito e ação se rompe. E o agente da ação e a ação mesma se desligam. Seja como for, opus Dei, isto é "O mistério litúrgico, enquanto alcança nele sua realização do mistério da economia trinitária, é o mistério da praxe e dessa operatividade" (AGAMBEN, 2013, p.37).

Amiúde a noção de mistério estará presente e com cada vez mais força na teologia cristã. Já no século $X X$ contra tudo aquilo que acreditava ameaçar o 
catolicismo - entenda o racionalismo, individualismo e sobretudo protestantismo Odo Casel e o Movimento Litúrgico trazem o mistério para o centro da reflexão teológica. Ademais a liturgia deixará de ser uma dentre tantas outras atividades exercidas pela igreja, e passará conforme preconiza o Movimento Litúrgico, ao cerne da vida eclesial. Como que reivindicando a necessidade de um "retorno ao mistério", Casel chega a afirmar que o cristianismo é em si mistério, e que a despeito de resumir-se em um conjunto de dogmas e doutrinas, concentra em si e revela-se como imagem e expressão da economia trinitária e, da ação redentora de Cristo. Para Agamben "Isso significa, se olharmos atentamente, que a Igreja é algo como uma comunidade política (Casel se serve da expressão 'comunidade cultual'), que se realiza plenamente só no cumprimento de uma ação especial que é a liturgia" (AGAMBEN, 2013, p.44).

Nesse sentido, considerando que a Igreja enquanto representação litúrgica e eficaz da presença misteriosa e salvífica da Trindade, é mistério em si, a teologia para compreender este mistério da liturgia cristã, terá de perscrutar as maneiras pelas quais essa tal presença misteriosa ocorre nas representações litúrgicas. Não obstante, lançando mão das reflexões que vão desde aquelas produzidas pela tradição patrística oriental, até os padres latinos e escolásticos, Casel apropria-se o termo effectus. A saber, este termo sintetiza a ideia na qual "O mistério litúrgico não se limita a representar a paixão de Cristo, mas representado-a, realiza seu efeitos, de maneira que se pode dizer que a presença de Cristo coincide nele integralmente com sua efetuabilidade" (AGAMBEN, 2013, p. 50). Em outras palavras, "effectus denomina, segundo Casel, essa unidade efetual de imagem e presença no mistério litúrgico, no qual a presença é real em sua operatividade" (AGAMBEN, 2013, p.49).

E neste momento a história da liturgia cristã exibe um aspecto imprescindível à reflexão filosófica ocidental acerca da ontologia. Conforme nos diz Castro, "Enquanto na concepção clássica, de fato, o ser como substância e acidente, é ser independentemente de seus efeitos, o ser da efetuabilidade é inseparável de seus efeitos" (CASTRO, 2012, p. 207). Sendo assim, ser e efetualidade se tornam sinônimos, o ser é só na medida em que agindo vai se efetuando como tal. Nas palavras de Agamben 
Se retornarmos agora à tese de Casel da qual partimos, não podermos senão registrar sua exatidão: effectus na linguagem litúrgica significa Wirklichkeit, um modo eminente da realidade e da presença. Esse modo da presença, é todavia, indiscernível de seus efeitos e de sua realização - é, no sentido que vimos, operatividade e praxe. Nessa perspectiva, é a essência mesma do mistério litúrgico que se esclarece: o mistério é o efeito, misteriosa é a efetualidade, enquanto nesta o ser se resolve em praxe e a praxe se substancializa em ser. O mistério da liturgia coincide, assim, integralmente com o mistério da operatividade. Em conformidade com a indeterminação de potência e ato, de ser e praxe, que está aqui em questão, essa coincidência é operativa, no sentido de que nela se realiza uma transformação decisiva na história da ontologia: a passagem a energeia para a efetualidade (AGAMBEN, 2013, p. 63).

Entrementes, não é tanto o termo "liturgia" que Agamben irá utilizar para designar essa praxe efetual que ele mesmo busca desvelar, mas, sim, o termo ciceroniano do officium. Este, não denota "uma obrigação jurídica ou moral nem uma pura e simples necessidade natural [...]: o officium é o que faz com que um indivíduo se comporte de modo consequente; como prostituta é-se prostituta, como vilão é-se vilão [...] e, mais tarde, como bispo é-se bispo" (AGAMBEN, 2013, p.80). Assim, para além das dimensões jurídicas ou morais, officium sinaliza uma importância antropológica, que de maneira específica vem a ser utilizado para opor o modo de vida dos seres humanos ao modo de vida dos animais. A despeito destes últimos, que se movem única e exclusivamente conduzidos por suas sensações imediatas, os humanos através de suas faculdades racionais, são capazes de governar a própria vida. Neste sentido, poderíamos dizer junto com Agamben, que mais especificamente, "officium é o que torna a vida governável, aquilo através do que a vida dos homens é 'instituída' e 'formada'” (AGAMBEN, 2013, p.82).

Todavia, é importante salientar conforme nos chama atenção Castro que

\begin{abstract}
a partir do deslocamento semântico levado a cabo por Santo Ambrósio, o termo 'ofício' será utilizado nos textos teológicos com um sentido amplo para referir-se a liturgia em geral e com outro mais restringido para falar especificamente do ministério do sacerdote. O conceito ciceroniano, retomado por Ambrósio, serviu então para articular a tensão antes mencionada entre ministério e ministério: efeito divino e ação de Deus produz na celebração dos sacramentos e a ação instrumental dos sacerdotes (CASTRO, 2012, p.209).
\end{abstract}

\footnotetext{
${ }^{6}$ Conforme afirma Agamben, Heidegger também percebeu a transformação da ontologia, que consiste na passagem da noção de energeia à efetualidade. Contudo, para Agamben, o filósofo de Meßkirch por considerar a fé cristã na Criação como sendo o catalisador metafísico desta passagem, não foi capaz de compreender que a essência metafísica da técnica, não seja tão somente a produção. Mas, sobretudo o governo e economia, a gestão dos homens e das coisas - tal qual, sugere o empreendimento agambeniano acerca das liturgias.
} 
E a tal ponto que ser e efeito, ontologia e praxe se tornem indiscerníveis. Afinal, como vemos no "oficio" "O effectus divino é determinado pelo ministério humano e este pelo effectus divino. [...]. Isso significa, porém, que o officium institui entre ser e praxe uma relação circular, pela qual o ser do sacerdote define sua praxe e esta, por sua vez, define o ser" (AGAMBEN, 2013, p.88). Ou seja, no officium o sacerdote tem o dever de ser o que é, e é na justa medida em que deve ser. Diríamos que o sacerdote - isto é, um sujeito cujo ser é um serviço a ser posto em obra -, é desde este ângulo uma liturgia em si. De qualquer forma, por mais que aquele problema teológico relativo a dignidade pessoal do sacerdote e o efeito de sua celebração, enfrentado pela Igreja primitiva, estivesse na medida do possível resolvido com a noção de "ofício", o paradigma ético fundado sobre a separação entre sujeito e ação, seguiria vigente. De tal modo que "um agir que consiste inteiramente em sua irredutível efetualidade e cujos efeitos não são, todavia, verdadeiramente imputáveis aos sujeitos que lhes põe em ser" (AGAMBEN, 2013, p.89).

No rastro destas intuições, Agamben ao deslocar suas atenções para o mundo latino de Varrão, constata que os magistrados romanos identificam o "ofício" a uma terceira e inédita modalidade do agir humano. Distintamente do facere e do agere aristotélico, se encontra portanto o gerere. Deste modo

\begin{abstract}
Enquanto, para Aristóteles, o paradigma da política é a praxe, gerere designa então o conceito especificamente romano da atividade daquele que é investido de uma função pública de governo. O imperator, o magistrado investido de um imperium, não age nem produz, sua ação não é definida, como o fazer, por um resultado externo (a obra) nem tem em si mesma seu fim: ela se define por seu próprio exercício, por seu assumir e executar uma função de ofício. [...] a ação coincide aqui com a efetuação de uma função que resta a ela mesma definir. O gerere é, nesse sentido, o paradigma do officium (AGAMBEN, 2013, p. 90). ${ }^{7}$
\end{abstract}

Não obstante, ao iluminar o paradigma do "ofício" com a noção de "comando", que caracteriza o ato próprio do imperador, Agamben, localiza uma similaridade. Tomando a natureza especial do "comando", o filósofo italiano afirma que assim

\footnotetext{
${ }^{7}$ Castro afirma que as análises feitas sobre Aristóteles, realizadas por Agamben em 0 homem sem conteúdo, mostram que "Aristóteles distinguia entre o gênero de ações cujo efeito ou fim é exterior à ação que os produz, a poiesis, e as ações cuja finalidade é a ação mesma, a práxis. O gerere, ao contrário, não é nem facere nem agere, mas antes o fato de assumir e sustentar uma carga pública ou função" (CASTRO, 2012, p.2010).
} 
como o "oficio", o "comando" não se caracteriza por ser propriamente um ato-em-si, afinal, para ser ato-mesmo, depende de algum outro lhe obedeça. Por isso, o "comando" "tem sentido somente enquanto toma por objeto e assume sobre si a ação de outro (que supostamente deve obedecer, isto é, seguir o comando)" (AGAMBEN, 2013, p. 90-91). Portanto, tanto aquele que segue uma ordem, quanto aquele que celebra um ato litúrgico, se constituem enquanto seres de comando. Isto é, "são determinados em seu ser por seu agir e vice-versa" (AGAMBEN, 2013, p. 91). A fim de ilustrar o que temos dito, tal como sugere Agamben, poderíamos pensar nas figuras do imperador e de um soldado: que são figuras interdependentes, por assim dizer. Respectivamente, o imperador só irá imperar, na medida em que seus comandos forem seguidos por seus comandados, e estes serão soldados, apenas e enquanto seguirem os comandos daquele que thes ordena. Ou seja, o ser do imperador que é comando se fundamenta no ser do soldado que é obediência a tais comandos e vice-versa.

Dito isso, após compreender a liturgia cristã desde a noção de "ofício", Agamben irá sinalizar a sua tese central em Opus Dei - tese esta que ele irá perscrutar no mais detidamente último capítulo de seu livro. A certa altura ele afirma,

\begin{abstract}
O influxo talvez mais decisivo que o officium como paradigma da praxe sacerdotal exerceu sobre a ontologia ocidental foi a transformação do ser em dever-ser e a consequente introdução do dever como conceito fundamental na ética. Reflita-se sobre a singular circularidade que vimos definir o officium. O sacerdote deve realizar seu ofício enquanto é sacerdote e é sacerdote enquanto realiza seu ofício. O ser prescreve a ação, mas a ação define integralmente o ser: isso e não outra coisa significa "dever-ser". O sacerdote é aquele ente cujo ser é imediatamente uma tarefa e um serviço - isto é, uma liturgia. [...]. A ação como liturgia, e esta como relação circular entre ser e praxe, entre ser e dever-ser: esse é o legado inquietante que a modernidade, do momento em que colocou o dever e o ofício no centro de sua ética e de sua política, mais ou menos conscientemente aceitou sem o benefício do inventário (AGAMBEN, 2013, p. 93).
\end{abstract}

Com vistas a realizar aquilo que ele mesmo define como sendo uma "genealogia do ofício", Agamben objetiva compreender a natureza dos atos litúrgicos, isto é a natureza de um ato que se define como "ofício". Destarte, "O fundo dessa genealogia é a tese, que empresta seu ao capítulo, segundo o qual existem no Ocidente duas ontologias: uma do dever-ser, do mando própria do âmbito 
religioso e jurídico, [...] e outra do ser, própria da ordem filosófica e científica" (CASTRO, 2012, p.2010). ${ }^{8}$

Nesse sentido, visando ultrapassar Schopenhauer e Nietzsche - autores que de acordo com Agamben, localizaram os "pressupostos teológicos escondidos" da filosofia moral de Kant, mas que não foram capazes de descrever satisfatoriamente os efeitos deste paradigma prático sobre a ação humana - Agamben retorna a Aristóteles. Ciente de que officium e effectus estão vinculados à noção de potênciaato, respectivamente dynamis e energeia, o filósofo italiano irá aproximar o modelo cristão do aristotélico. E o que descobrirá a partir disso é que a doutrina dos habitus de Aristóteles se articula harmoniosamente com a doutrina das virtudes dos escolásticos medievais. E que não obstante, ambas por suas vez, serão assimiladas e transformadas por Kant, especificamente a partir da noção de "dever de virtude". "Desse modo, vale sublinhá-lo, o kantismo não é apresentado como uma ruptura a respeito da escolástica, mas como uma continuação" (CASTRO, 2013, p. 211).

Por nossa vez, sondando os modos pelos quais o dever entrou na ética, sigamos o percurso traçado por Agamben. Conforme sabemos, para Aristóteles o ser se divide em potência e ato; isso quer dizer que estas são as duas maneiras que o ser se revela. A exemplo, poderíamos citar a genérica potencialidade humana de aprender a tocar um instrumento musical. Seguindo este raciocino - ao aprender tocar determinado instrumento, a pessoa converteria aquilo que até então era mera potencialidade, em ato. Sendo assim, o hábito (héxis) seria justamente o vetor desta passagem. Ou seja, o hábito representa a figura intermediária pela qual a potência se transforma em ato. Voltando ao nosso exemplo musical, diríamos que o hábito é a técnica-ciência que levou nosso potencial musicista, ao estatuto de músico. Portanto, através do conceito de hábito, potência e ato apesar de configurarem maneiras distintas do ser, conservam uma tal relação de reciprocidade. Nele, encontramos "o ponto no qual o ser transpassa a ter" (AGAMBEN, 2013, p.99).

Todavia é importante salientar que para Aristóteles ter uma potência, é sinônimo de poder não transformá-la em ato. Nesse sentido, possui verdadeira potência somente quem pode ou não colocá-la em ato. Em outras palavras, apenas

\footnotetext{
${ }^{8} \mathrm{O}$ título do quarto e último capítulo da referida obra de Agamben é: As duas ontologias, ou como o dever entrou na ética.
} 
um músico tem a opção de escolher não tocar seu instrumento. Por isso, é assertivo dizer que toda potência é também potência de-não, ou impotência.

Acontece que desde já, se delineia um outro problema. Isso pois, se até então a noção de hábito havia dado conta de assegurar conceitualmente a passagem da potência ao ato, agora que sabemos que toda potência é potência de-não, há que identificarmos o que determinaria a passagem da impotência à potência. $E$ é novamente em Aristóteles, que Agamben encontra respostas. Especificamente sobre a teoria das virtudes, diz Agamben

A teoria das virtudes é a resposta ao problema da inoperosidade do hábito, [...]. A virtude (areté) é, de fato, 'um certo hábito' e, ao mesmo tempo, algo que, no hábito o torna capaz de passar ao ato e agir de melhor modo. [...], essa espécie de hábito que é a virtude pode obter esse resultado [...], senão através do frequente exercício que o transforma em 'habitude' (ethos) (AGAMBEN, 2013, p.102).

Mas, a despeito dos esforços do estagirita, Agamben assiná-la uma certa persistência da aporeticidade da teoria aristotélica das virtudes. Como atestam as palavras de Castro "Essa noção, de fato, aparece para explicar a passagem da potência genérica ao ato, porém por si só não basta para dar conta disso. Um hábito, por definição, pode permanecer na forma da inoperosidade" (CASTRO, 2012, p. 211). E justamente aqui, sobre este "fundo aporético da ética aristotélica que a teoria escolástica das virtudes em sua relação com o officium torna-se plenamente inteligível" (AGAMBEN, 2013, p.103). Para expor como isso é possível, Agamben remonta Tomás de Aquino, que ao desenvolver seu tratado das virtudes, elaborou uma sofisticada teorização acerca dos habitus.

De acordo com Tomás o hábito é uma forma de potência especificamente humana. Haja vista que a natureza, ao ser determinada por uma só operação, prescinde de qualquer hábito. Do contrário como dissemos, os humanos por sua vez, dependem de um princípio que eleve a potência em ação. Diferentemente do fogo que não possui a potência de não esquentar, o músico tal qual no exemplo anterior, se acaso o desejar tem a possibilidade de escolher não tocar seu instrumento. Acontece que também a despeito dos agentes naturais, cujas ações derivam exclusivamente de princípios ativos gerais que jamais podem ser negados por serem "inatos" - como a quentura do fogo por exemplo -, os atos humanos 
produzem hábitos. Portanto, seria essa passividade que dispõem os agentes humanos, que de acordo com Tomás fundamentaria o habitus. Ademais, se por um lado encontramos a passividade como sendo o fundamento do habitus, por outro, não podemos negligenciar a ação que lhe é sobremaneira definidora.

A esta altura, em um verdadeiro corpo a corpo com Aristóteles, o Aquinate a fim de resolver aquela tal aporia aristotélica, acaba por lançar mão de sua teoria das virtudes. E levando-a ao extremo, ele irá decretar o caráter essencialmente operativo do hábito. De tal forma que em Tomás a virtude se torna um hábito essencialmente operativo que se encarregaria de transpor a passividade à ação. Seja como for, conforme nos lembra Agamben "Dado que, contudo, um hábito pode ser operativo também com relação ao mal, é necessário que o hábito virtuoso possa ser definido como 'bom'” (AGAMBEN, 2013, p. 105). Assim, para além de garantir o caráter operativo do hábito, "A bondade da virtude é sua efetualidade, seu impelir e orientar a potência em direção a sua perfeição" (AGAMBE, 2013, p. 105). E se é perfeito e bom, é não porque possui um objeto bom, mas tão somente por que condiz com a natureza do agente que o exerce.

Conseguinte como podemos constatar, a doutrina das virtudes de São Tomas é convergente com aquela do officium. Nas palavras de Agamben

\begin{abstract}
Nesse sentido, a definição da virtude apresenta mais do que uma analogia com a circularidade que caracteriza a efetualidade do officium. $\mathrm{O}$ sacerdote deve realizar seu oficio enquanto é sacerdote, mas é sacerdote enquanto realiza seu ofício. [...] Tanto o ofício quanto a virtude são retidos no mesmo círculo: o bom (virtuoso) é tal porque age bem e age bem porque é bom (virtuoso) (AGAMBEN, 2013, p.106).
\end{abstract}

Respectivamente, aprofundando o pensamento tomasiano acerca de sua doutrina das virtudes, Agamben nos revela que o "ponto-máximo" por assim dizer, no qual o pensamento de Tomas une officium e virtude é a teoria da religio. A saber, uma vez que a religião é um dever - que sumariamente consiste no ato de devolver honras e glórias que são devidas à Deus -, para o Doutor Angélico ela se caracteriza por ser uma virtude máxima! E tal como na circularidade do officium, a religião como virtude, na medida em que é execução de um "dever-bom", ao ser exercida, torna 
imediatamente bom o agente que as pratica. ${ }^{9}$ Se até então, o "ofício" era uma virtude, de agora em diante com status religionis de Tomás de Aquino, a virtude que atingiu o grau de dever irá desfazer o caráter aporético da teoria que Aristóteles havia deixado em suspenso. Conforme sintetiza Agamben

No conceito de uma virtude cujo único objeto é o debitum, de um ser que coincide integralmente com um ter de ser, virtude e officium coincidem sem resíduos. O dever-ser é, portanto, o dispositivo que permite aos teólogos resolver a circularidade entre ser e agir na qual restava presa a doutrina das virtudes. $\mathrm{O}$ ato realizado graças à inclinação operativa do hábito virtuoso é, na realidade e na mesma medida a execução de um dever. Fazendo literalmente 'da necessidade virtude', o religioso é, ao mesmo tempo, inclinado ao dever e obrigado à virtude (AGAMBEN, 2013, p.109)

Contudo, segundo o diagnóstico de Francisco Suárez - outro teólogo medieval analisado por Agamben em Opus Dei - a virtude da religião, por mais excelente que seja, jamais poderá solver seu débito para com o Summum Bonum. Por isso, de acordo com tal pensamento o dever para com Deus equivale a uma dívida impagável. Dessa maneira, por se tratar de um ideal inatingível, o dever religioso é elevado à categoria de um dever infinito.

Mais tarde, especificamente em Kant - quando o afã iluminista esboçar a fundamentação de uma ética-filosófica apartada de ingerências religiosas -, a ideia de "dívida infinita" proveniente da teologia escolástica, irá se camuflar com a ontologia do dever-ser, se instalando indelevelmente no cerne da metafísica ocidental. De tal modo que "Se no ofício a garantia da efetualidade da ação litúrgica ex opere operato está em Cristo, o que em Kant toma o lugar de Cristo como garantia do dever é a lei" (AGAMBEN, 2013, p.117). Malgrado na esteira destes pressupostos metafísicos, o "respeito" pela lei moral, é o dispositivo kantiano que tornaria operativo no homem aquela consciência para com o dever da obediência à lei que apriori é boa em si mesma. Finalmente, sintetiza Agamben

No limiar da modernidade, quando a teologia e a metafísica parecem ceder definitivamente o campo para a racionalidade científica, o pensamento de Kant representa o ressurgimento secularizado da ontologia do esto no seio da ontologia do esti, o ressurgir catastrófico do direito e da religião no seio da filosofia. Diante do triunfo da consciência científica, Kant procurou assegurar a sobrevivência da metafísica, enxertando e deixando agir a

\footnotetext{
${ }^{9}$ A devotio ou devoção é aquilo que no pensamento de Tomás asseguraria a agilidade na presteza deste dever para com Deus.
} 
ontologia do comando e do dever-ser naquela do ser e da substância. Crendo assegurar desse modo a possibilidade da metafísica fundar, ao mesmo tempo, uma ética não jurídica nem religiosa, ele, por um lado, acolheu sem dar-se em conta a hereditariedade da tradição teológicoliturgica do officium e da operatividade e, por outro, demitiu permanentemente a ontologia clássica (AGAMBEN, 2013, p.126).

Diríamos então, ao final deste longo percurso, conforme torna evidente a obra aqui analisada, que o virtuoso de Kant - assim como na ácida analogia de Agamben para com o sujeito ético moderno -, é semelhante a um masoquista. Isto é, um sujeito submisso que obedece aos comandos da lei pelo simples fato de ter de se encontrar neste dever-sujeitar-se-à. Um alguém, cujo ser não é ser, a não ser que seja, na exata medida em que se submete a um governo e atua um tal dever-ser. ${ }^{10}$

\section{CONSIDERAÇÕES FINAIS}

Em outro texto, dirá Agamben que a comunidade que vem, tem o desafio eminente de pensar uma ética e uma política para além daquela que os dispositivos teológicos no Ocidente, secularizaram na gloriosa ontologia do dever-ser ${ }^{11}$. E isso por uma razão bem específica: em Opus Dei, Agamben atrevendo-se profanar a ética, entrega à polis algumas das pistas que poderão Ihe auxiliar no árdua tarefa que terão pela frente - isto é, a reinvenção de seus modos de vida.

Como vemos ao descortinar e exibir o vazio ético em que se erige o edifício filosófico moderno, temos revelado diante de nossos olhos que a despeito dos esforços metafísicos empreendidos e encenados nas performances litúrgicas contemporâneas, ao humano já não sobraria nenhuma essência a ser realizada, vocação política ou espiritual a ser perseguida, ou sequer uma obra por conceber. Enquanto um qualquer, para usar um conceito caro ao filósofo, o humano seria um aberto.

Enfim, se diante disso ainda nos resta algum dever, teríamos de perguntar a Agamben. Por nossa vez, e se é que o entendemos bem, diríamos que pela frente

\footnotetext{
${ }^{10}$ Para Agamben, a "teoria do puro direito" de Hans Kelsen - para quem ser e dever-ser constituem dados imediatos de nossa consciência -, e o tenente coronel da SS Adolf Eichmann - que a certa altura de seu famigerado interrogatório em Jerusalém afirmou ter vivido criteriosamente toda a sua vida segundo os preceitos da moral kantiana -, são as evidencias contemporâneas de que a ontologia do comando de Kant permanece vigente.

${ }^{11}$ AGAMBEN, Giorgio. A comunidade que vem. Autêntica: São Paulo. 2013a.
} 
vemos a emergência de um pensamento que conceba o humano desde outras representações, longe das subsunções biológicas, históricas e morais que até aqui tem persistido. Um ser que por assim dizer, não seja nem efetividade, nem eficiência, nem tampouco governo. Seja lá como for, como sugeriu Antonio Negri, só nos resta dizer: que belo enigma Agamben nos deu, não? ${ }^{12}$

\section{REFERENCIAS}

AGAMBEN, Giorgio. A comunidade que vem. São Paulo: Autêntica, 2013a.

. Opus Dei: arqueologia do ofício. São Paulo: Boitempo, 2013.

CASTRO. Edgardo. Introdução a Giorgio Agamben: uma arqueologia da potência. São Paulo: Autêntica, 2012.

Artigo recebido em: 21/10/2016

Artigo aprovado em: 25/05/2017

\footnotetext{
${ }^{12}$ NEGRI. Antonio. O sacro dilema do inoperoso. Disponível em $<$ https://blogdaboitempo.com.br/2013/07/11/o-sacro-dilema-do-inoperoso-a-proposito-de-opus-deide-giorgio-agamben/>.
} 